\title{
Betulinic acid regulates generation of neuroinflammatory mediators responsible for tissue destruction in multiple sclerosis in vitro
}

\author{
Jana BLAŽEVSKI 1, \#, Filip PETKOVIĆ1, \#, Miljana MOMČILOVIĆ ${ }^{1}$, Reinhard PASCHKE², Goran N KALUĐEROVIĆ2, ${ }^{3}$, Marija MOS- \\ TARICA STOJKOVIĆ4 , Djordje MILKOVIĆ ${ }^{1, *}$ \\ ${ }^{1}$ Department of Immunology, Institute for Biological Research "Siniša Stanković, University of Belgrade, Serbia; ${ }^{2}$ Biozentrum, Martin- \\ Luther-Universität Halle-Wittenberg, Weinbergweg 22, 06120 Halle (Saale), Germany; ${ }^{3}$ Institut für Chemie, Martin-Luther-Universität \\ Halle-Wittenberg, Kurt-Mothes Str 2, 06120 Halle (Saale), Germany; Institute for Microbiology and Immunology, School of Medicine, \\ University of Belgrade, Serbia
}

Aim: To investigate the influences of betulinic acid (BA), a triterpenoid isolated from birch bark, on neuroinflammatory mediators involved in the pathogenesis of multiple sclerosis and experimental autoimmune encephalomyelitis in vitro.

Methods: Encephalitogenic T cells were prepared from draining lymph nodes and spinal cords of Dark Agouti rats 8 to $10 \mathrm{~d}$ after immunization with myelin basic protein (MBP) and complete Freund's adjuvant. Macrophages were isolated from the peritoneal cavity of adult untreated rats. Astrocytes were isolated from neonatal rat brains. The cells were cultured and then treated with different agents. IFN-y, IL-17, iNOS and CXCL12 mRNA levels in the cells were analyzed with RT-PCR. iNOS and CXCL12 protein levels were detected using immunoblot. NO and ROS generation was measured using Griess reaction and flow cytometry, respectively.

Results: In encephalitogenic T cells stimulated with MBP $(10 \mu \mathrm{g} / \mathrm{mL})$, addition of BA inhibited IL-17 and IFN-y production in a dosedependent manner. The estimated IC ${ }_{50}$ values for IL-17 and IFN $\gamma$ were 11.2 and $63.8 \mu \mathrm{mol} / \mathrm{L}$, respectively. When the macrophages were stimulated with LPS $(10 \mathrm{ng} / \mathrm{mL})$, addition of BA (50 $\mathrm{mmol} / \mathrm{L})$ significantly increased ROS generation, and suppressed NO generation. The astrocytes were stimulated with ConASn containing numerous inflammatory mediators, which mimicked the inflammatory milieu within CNS; addition of BA (50 $\mathrm{mmol} / \mathrm{L})$ significantly increased ROS generation, and blocked ConASn-induced increases in iNOS and CXCL12 mRNA levels, but did not affect iNOS and CXCL12 protein levels. Importantly, in both the macrophages and astrocytes, addition of BA $(50 \mu \mathrm{mol} / \mathrm{L})$ inhibited lipid peroxidation.

Conclusion: Besides inhibiting encephalitogenic T cell cytokines and reducing NO generation, BA induces tissue-damaging ROS generation within CNS.

Keywords: betulinic acid; experimental autoimmune encephalomyelitis; multiple sclerosis; neuroinflammation; T cell; macrophage; astrocyte; cytokines; NO; ROS; CXCL12

Acta Pharmacologica Sinica (2013) 34: 424-431; doi: 10.1038/aps.2012.181; published online 4 Feb 2013

\section{Introduction}

Multiple sclerosis (MS) is a chronic inflammatory, demyelinating and degenerative disease of the CNS which affects more than two million people worldwide and represents a leading cause of non-traumatic neurologic disability in young adults. The autoimmune nature of MS pathology is substantiated by evidence obtained in its laboratory analogue,

\footnotetext{
\# The two authors contributed equally to this work.

* To whom correspondence should be addressed.

E-mail georgije_zw@yahoo.com

Received 2012-07-03 Accepted 2012-12-05
}

experimental autoimmune encephalomyelitis $(\mathrm{EAE})^{[1]}$. The widely accepted mechanism of EAE and MS pathogenesis suggests that encephalitogenic proteins or cross-reactive antigens in the periphery prime autoreactive $\mathrm{CD} 4^{+} \mathrm{T}$ cells $(\mathrm{T}$ helper, Th), which differentiate into effector Th1 and Th17 cells specific for myelin antigens and then migrate to the $\mathrm{CNS}^{[2]}$. On reactivation by target antigen in the CNS, Th1 and Th17 cells induce inflammation through the production of various mediators, including their signature cytokines, IFN- $\gamma$ and IL-17, respectively ${ }^{[2]}$. Both resident (astrocytes, microglia) and hematogenous (macrophages) cells respond to Th cytokines, further generating inflammatory mediators, such 
as nitric oxide (NO) and reactive oxygen species (ROS) ${ }^{[3-5]}$. Reactive oxygen and nitrogen species largely contribute to tissue destruction in MS and $\mathrm{EAE}^{[5-7]}$. $\mathrm{NO}$ also restrains the encephalitogenic $\mathrm{T}$ cell response ${ }^{[8]}$. Astrocytes are intensively involved in limiting the encephalitogenic immune response ${ }^{[9]}$. For instance, they express CXCL12, which has been attributed an anti-inflammatory role in neuroinflammation ${ }^{[10]}$.

Although several drugs approved for therapy of MS patients have demonstrated respectable efficacy and safety, MS is still an incurable disease. These drugs alter the natural course of MS but their long-term impact on its progression is uncertain and different adverse effects of such therapies have been described ${ }^{[11]}$. Therefore, additional treatments that may curtail MS attacks or improve the neurological functions of the patients, including complementary therapy, have to be explored. Natural products are the organic molecules that are produced by living organisms. They have been used as traditional remedies or supplementary diet constituents from ancient times. Also, numerous natural products have become conventional therapeutics, eg penicillin and taxol. Betulinic acid [3b, hydroxy-lup-20(29)-en-28-oic acid), BA] is a naturally occurring pentacyclic triterpene that exhibits a variety of biological activities, including antimicrobial, anti-inflammatory, anticancer and antioxidant properties ${ }^{[12,13]}$. BA is widely distributed in the plant kingdom, eg substantial amounts of BA are present in the outer bark of birch trees. White birch bark has been used by Native Americans as a folk medicine, while the reduced BA betulin (3b-lup-20(29)-en-3, 28-diol), was one of the first natural products to be identified and isolated from plants in 1788.

The influence of BA on neuroinflammation has not been investigated so far. Here, we analyzed its influence on key mechanisms in neuroinflammation, including IFN- $\gamma$ and IL-17 release form $\mathrm{T}$ cells, $\mathrm{NO}$ and ROS generation in macrophages and astrocytes and CXCL12 expression in astrocytes. A profound effect of BA on the examined parameters was observed, thus suggesting that BA could have a potent effect on neuroinflammation.

Table 1. Cell culture conditions.

\begin{tabular}{llllll}
\hline Cells & Number/well & V/well $(\mathrm{mL})$ & Plate & Stimulation & Read-out \\
\hline SPC & $5.0 \times 10^{6}$ & 1 & 24 -well & ConA $2.5 \mu \mathrm{g} / \mathrm{mL}$ & MTT assay, Griess reaction \\
DLNC & $2.5 \times 10^{6}$ & 1 & 24 -well & MBP $10 \mathrm{ng} / \mathrm{mL}$ & AP assay, ELISA, RT-PCR \\
PC & $2.0 \times 10^{6}$ & 1 & 24 -well & LPS $10 \mathrm{ng} / \mathrm{mL}$ & CV assay, Griess reaction \\
PC & $2.0 \times 10^{6}$ & 1 & 24 -well & LPS $10 \mathrm{ng} / \mathrm{mL}$ & Cytofluorimetry \\
PC & $4.0 \times 10^{6}$ & 1.5 & 24 -well & LPS $10 \mathrm{ng} / \mathrm{mL}$ & TBARS assay \\
MGC & $1.5 \times 10^{5}$ & 1 & 24 -well & ConASn $20 \%$ & Cytofluorimetry \\
Astrocytes & $1.5 \times 10^{5}$ & 1 & 24 -well & ConASn $20 \%$ & Cytofluorimetry \\
Astrocytes & $0.7 \times 10^{6}$ & 1.5 & 6 -well & ConASn $20 \%$ & TBARS assay \\
Astrocytes & $1.5 \times 10^{5}$ & 1 & 24 -well & ConASn $20 \%$ & RT-PCR, immunoblot \\
C6 cells & $1.5 \times 10^{5}$ & 1 & 24 -well & ConASn $20 \%$ & Cytofluorimetry \\
C6 cells & $1.5 \times 10^{5}$ & 1 & 24 -well & ConASn $20 \%$ & Immunoblot \\
C6 cells & $1.0 \times 10^{6}$ & 1.5 & 6-well & ConASn $20 \%$ & TBARS assay \\
SCC & $0.5 \times 10^{6}$ & 0.2 & 96 -well & No & MTT assay, ELISA \\
\hline
\end{tabular}

\section{Materials and methods Reagents}

RPMI-1640 medium and fetal calf serum (FCS) were from PAA Laboratories (Pasching, Austria). DMSO was from SigmaAldrich (St Louis, MO). BA was a kind gift from BioSolutions Halle $\mathrm{GmbH}$.

\section{Cells and cell cultures}

Dark Agouti rats were obtained from the Animal House Facility of the Institute for Biological Research "Siniša Stanković", Belgrade, Serbia. All experimental procedures were approved by the Institutional Animal Care and Use Committee of the institute (App № 02.1/09-01-348). Cells were maintained in HEPES-buffered RPMI-1640 medium with 5\% FCS, 2 mmol/L L-glutamine, antibiotics, and sodium pyruvate (culture medium). Spleen cells (SPC) and peritoneal cells (PC) were isolated from healthy, untreated rats. Draining lymph node cells (DLNC) were obtained from popliteal lymph nodes at 8-10 d and inflammatory cells were obtained from the spinal cord (SC) at 12-14 d after immunizing the rats with myelin basic protein (guinea pig MBP, kind gift from Professor Alexander Fluegel, University of Goettingen, Germany) and complete Freund's adjuvant (CFA, Difco, Detroit, MI). Lymph nodes and spleen were mechanically disrupted, passed through a $40-\mu \mathrm{m}$ nylon mesh filter and the resulting suspension was collected by centrifugation. Red blood cells from the single cell suspensions obtained from the spleens were lysed using RBC Lysis Buffer (eBioscience, San Diego, CA). PC were obtained by lavage of the peritoneal cavity with ice-cold PBS. Rats were perfused with sterile PBS before SC extraction. SC was homogenized, adjusted to $40 \%$ Percoll (Sigma-Aldrich) and overlaid on a $70 \%$ Percoll gradient. Following centrifugation at $870 \times g$ for 50 min the SC cells (SCC) were recovered from the $40 \% / 70 \%$ Percoll interface and washed in the culture medium. Astrocytes were isolated from mixed glial cell (MGC) cultures prepared from the brains of newborn rats as previously described ${ }^{[14]}$. Astrocytes were grown in the culture medium supplemented with $4 \mathrm{~g} / \mathrm{L}$ glucose and they were 
purified by repetition of trypsinization $(0.25 \%$ trypsin and $0.02 \%$ EDTA) and re-plating. The cells used in these experiments were obtained after a third or fourth passage. The rat C6 astrocytoma cell line (kindly donated by Dr P Tranque, Universidad de Castilla-La Mancha, Albacete, Spain) was maintained in the culture medium until it was used for the experiments. Details of the cell culturing conditions are given in Table 1. PC were left at $37^{\circ} \mathrm{C}$ for $2 \mathrm{~h}$ and then non-adherent cells were removed by intensive washing of the wells with PBS, thus leaving adherent cells (macrophages) in the cultures. ConA and LPS (E coli 055:B5) were from Sigma-Aldrich (St Louis, MO). ConASn was a supernatant obtained from cultures of SPC stimulated with ConA $(2.5 \mu \mathrm{g} / \mathrm{mL})$ for $48 \mathrm{~h}$.

\section{Cell viability assays}

DLNC viability was determined using an acid phosphatase (AP) assay. The AP substrate contained $11 \mathrm{mg} / \mathrm{mL}$-nitrophenylphosphate, $4 \mu \mathrm{L} / \mathrm{mL}$ Triton- $X$ and $0.3 \%$ sodium acetate. $100 \mu \mathrm{L}$ of the substrate was added to $200 \mu \mathrm{L}$ of the cell culture supernatants, directly into the cell cultures, and the cultures were incubated at $37^{\circ} \mathrm{C}$ for $2 \mathrm{~h}$. The AP reaction was stopped with $100 \mu \mathrm{L}$ of $1.3 \mathrm{~mol} / \mathrm{L} \mathrm{NaOH}$. In order to assess the viability of the SPC and SCC we used the mitochondrialdependent reduction of 3-(4,5-dimethylthiazol-2-yl)-2,5diphenyl-tetrazolium bromide (MTT) to formazan. At the end of the appropriate treatments, the cells were collected in tubes, centrifuged, supernatants removed and the cell pellets was dissolved in a $0.5 \mu \mathrm{g} / \mathrm{mL}$ MTT (Sigma-Aldrich) solution. Incubation with MTT lasted for $30 \mathrm{~min}$ at $37^{\circ} \mathrm{C}$ and cells were centrifuged once more. DMSO was added to the pellets to dissolve the formazan crystals. In order to determine the viability of the PC, crystal violet $(\mathrm{CV})$ staining was performed. Cell culture supernatants were collected and the cells were fixed with methanol (10 $\mathrm{min}$ at room temperature). Subsequently, cells were stained with CV solution (2\% in PBS $v / v$, $10 \mathrm{~min}$, room temperature) and then thoroughly washed with tap water. Finally, the crystal violet dye remaining in the cells was dissolved in 33\% acetic acid. Absorbance in the AP assay was measured at $405 \mathrm{~nm}$ and in the MTT assay and CV assay it was measured at $570 \mathrm{~nm}$, with a correction at $690 \mathrm{~nm}$, using an automated microplate reader (LKB 5060-006, LKB, Vienna, Austria).

\section{ELISA}

Cytokine concentration in the cell culture supernatants was determined by sandwich ELISA using MaxiSorp plates (Nunc, Rochild, Denmark) and anti-cytokine paired antibodies according to the manufacturer's instructions. Samples were analyzed in duplicate for murine/rat IL-17 (eBioscience) and rat IFN-ץ (R\&D, Minneapolis, MN, USA). The results were calculated using standard curves made on the basis of known concentrations of the appropriate recombinant cytokines.

\section{Immunoblot}

Whole-cell lysates were prepared in a solution containing 62.5
mmol/L Tris- $\mathrm{HCl}(\mathrm{pH} 6.8), 2 \%$ w/v sodium dodecyl sulfate (SDS), $10 \%$ glycerol, $50 \mathrm{mmol} / \mathrm{L}$ dithiothreitol (DTT), $0.01 \%$ $w / v$ bromophenol blue, $1 \mathrm{mmol} / \mathrm{L}$ phenylmethanesulphonylfluoride or phenylmethylsulphonyl fluoride (PMSF), $1 \mu \mathrm{g} / \mathrm{mL}$ aprotinine, and $2 \mathrm{mmol} / \mathrm{L}$ EDTA. Samples containing $20 \mu \mathrm{g}$ of proteins (measured by Lowry protein assay) were electrophoresed on a $12 \%$ SDS-polyacrylamide gel for iNOS detection or on a $15 \%$ gel for CXCL12 detection. The samples were electro-transferred to polyvinylidene difluoride membranes at $5 \mathrm{~mA} / \mathrm{cm}^{2}$, using a semi-dry blotting system (Fastblot B43, Biorad, Muenchen, Germany). The blots were blocked with $5 \%$ w $v$ nonfat dry milk in PBS containing $0.1 \%$ Tween-20 and probed with specific antibodies to iNOS (Sigma-Aldrich, USA), to CXCL12 (Santa Cruz Biotechnology, Santa Cruz, CA, USA) and to $\beta$-actin (Abcam, Cambridge, England, UK), followed by incubation with secondary antibody at a 1:10000 dilution [ECL donkey anti-rabbit horseradish peroxidase (HRP)-linked, GE Healthcare, Buckinghamshire, England, UK]. Detection was performed using chemiluminescence (ECL, GE Healthcare) and photographs were made by X-ray films (Kodak, Rochester, NY). Densitometry was performed with Scion Image Alpha 4.0.3.2 (Scion Corporation, Frederick, MD). Results are presented relative to $\beta$-actin.

\section{Measurement of NO release and ROS detection}

Nitrite accumulation, as an indirect measure of NO release, was determined in cell culture supernatants using the Griess reaction. In brief, triplicate aliquots of cell-free supernatants were mixed with an equal volume of Griess reagent, of a 1:1 mixture of $0.1 \%$ naphthylethylenediamine dihydrochloride (Sigma-Aldrich) and of 1\% sulphanilamide (Sigma-Aldrich) in $5 \% \mathrm{H}_{3} \mathrm{PO}_{4}$. The absorbance at $570 \mathrm{~nm}$ was determined in a microplate reader (LKB 5060-006; LKB) and compared to a standard curve for $\mathrm{NaNO}_{2}$. ROS generation was measured by flow cytometry. Astrocytes, MGC, C6 cells and PC were incubated in the presence of $1 \mu \mathrm{mol} / \mathrm{L}$ dihydrorhodamine 123 (DHR, Sigma-Aldrich, USA) for 30 min prior to treatment and then treated for $1 \mathrm{~h}$. Subsequently, the cells were washed twice in PBS and green fluorescence was analyzed with a FACSCalibur flow cytometer (BD, Heidelberg, Germany) using the Cell Quest Pro software (BD).

\section{Determination of lipid peroxidation (TBARS assay)}

Lipid peroxidation products were quantified by measuring thiobarbituric acid reactive substances (TBARS) ${ }^{[15]}$. One $\mathrm{mL}$ of $20 \%(w / v)$ trichloroacetic acid containing $0.8 \%(w / v)$ thiobarbituric acid was added to each culture dish. The cells were scratched off with a cell scraper, the suspensions were transferred to glass centrifuge tubes and incubated at $95^{\circ} \mathrm{C}$ for 45 min. After cooling to room temperature and centrifugation the absorbance of the supernatant at $535 \mathrm{~nm}$ was determined. In parallel, known concentrations of malondialdehyde (MDA) were used for standard curve construction. Also, parallel cultures of cells were used to determine cell viability by CV staining. Results are presented as relative values ( $\mu \mathrm{mol} / \mathrm{L}$ of MDA normalized to absorbance values determined in the CV test). 
Reverse transcription-real time polymerase chain reaction

In order to determine gene expression real time RT-PCR was performed. First, total RNA was isolated from DLNC $\left(5 \times 10^{6}\right.$ cells) or astrocytes $\left(1.5 \times 10^{5}\right)$ using an mi-Total RNA Isolation Kit (Metabion, Martinsried, Germany) and reverse transcribed using random hexamer primers and MMLV (Moloney Murine Leukemia Virus) reverse transcriptase, according to the manufacturer's instructions (Fermentas, Vilnius, Lithuania). Prepared cDNAs were amplified using a Maxima ${ }^{\circledR}$ SYBR Green qPCR Master Mix (Fermentas) according to the recommendations of the manufacturer in a total volume of $20 \mu \mathrm{L}$ in an ABI PRISM 7000 Sequence Detection System (Applied Biosystems, Foster City, CA). Thermocycler conditions comprised an initial step at $50^{\circ} \mathrm{C}$ for $5 \mathrm{~min}$, followed by a step at $95^{\circ} \mathrm{C}$ for 10 min and a subsequent 2-step PCR program at $95^{\circ} \mathrm{C}$ for $15 \mathrm{~s}$ and $60^{\circ} \mathrm{C}$ for $60 \mathrm{~s}$ for 40 cycles. The PCR primers (Metabion) were as follows: $\beta$-actin forward primer $5^{\prime}$-GCT TCT TTG CAG CTC CTT CGT-3'; $\beta$-actin reverse primer 5'-CCA GCG CAG CGA TAT CG-3'; IFN- $\gamma$ forward primer 5'-TGG CAT AGA TGT GGA AGA AAA GAG-3'; IFN- $\gamma$ - reverse primer 5'-TGC AGG ATT TTC ATG TCA CCA T-3'; IL-17 forward primer 5'-ATC AGG ACG CGC AAA CAT G-3'; IL-17 reverse primer 5'-TGA TCG CTG CTG CCT TCA C-3'; CXCL12 forward primer 5'-GAT TCT TTG AGA GCC ATG TC-3'; CXCL12 reverse primer 5'-GTC TGT TGT TGC TTT TCA GC-3'; iNOS forward primer 5'-TTC CCA TCG CTC CGC TG-3', iNOS reverse primer 5'-CCG GAG CTG TAG CAC TGC A-3'. The accumulation of PCR products was detected in real time and the results were analyzed using the 7500 System Software (Applied Biosystems) and presented as $2^{-\Delta \mathrm{Ct}}, \Delta \mathrm{Ct}$ being the difference between $\mathrm{Ct}$ values of specific genes and the endogenous control ( $\beta$-actin).

\section{Statistical analysis}

A Student's $t$ test was performed for statistical analysis. A $P$ value less than 0.05 was considered statistically significant.

\section{Results}

The effect of BA on IFN- $\gamma$ and IL-17 generation in encephalitogenic $T$ cells

DA rats were immunized with MBP and CFA. Eight to ten days after immunization DLNC were isolated and stimulated in vitro with MBP for $24 \mathrm{~h}$. BA applied simultaneously with MBP did not significantly affect DLNC viability in concentrations up to $100 \mu \mathrm{mol} / \mathrm{L}$ (Figure 1A). However, it did affect IFN- $\gamma$ and IL-17 production in DLNC in a dose dependent manner (Figure 1A). Inhibition of IL-17 was achieved with lower concentrations of BA than required for the reduction of IFN- $\gamma$ (estimated $\mathrm{IC}_{50}$ values were $11.2 \mu \mathrm{mol} / \mathrm{L}$ for IL-17 and $63.8 \mu \mathrm{mol} / \mathrm{L}$ for IFN-ү). Indeed, when we applied $50 \mu \mathrm{mol} / \mathrm{L}$ BA it markedly reduced IL-17 production, but less efficiently reduced IFN- $\gamma$ production in DLNC (Figure 1B). Moreover, 50 $\mu \mathrm{mol} / \mathrm{L}$ BA intensively down-regulated IL-17 gene expression, while the reduction of IFN- $\gamma$ gene expression was not statistically significant (Figure 1C). Still, applied in $100 \mu \mathrm{mol} / \mathrm{L}$, BA almost completely diminished IFN- $\gamma$ release from DLNC

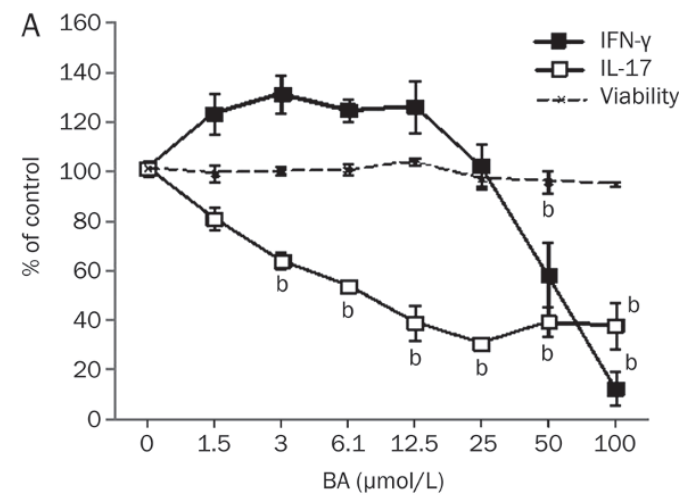

B
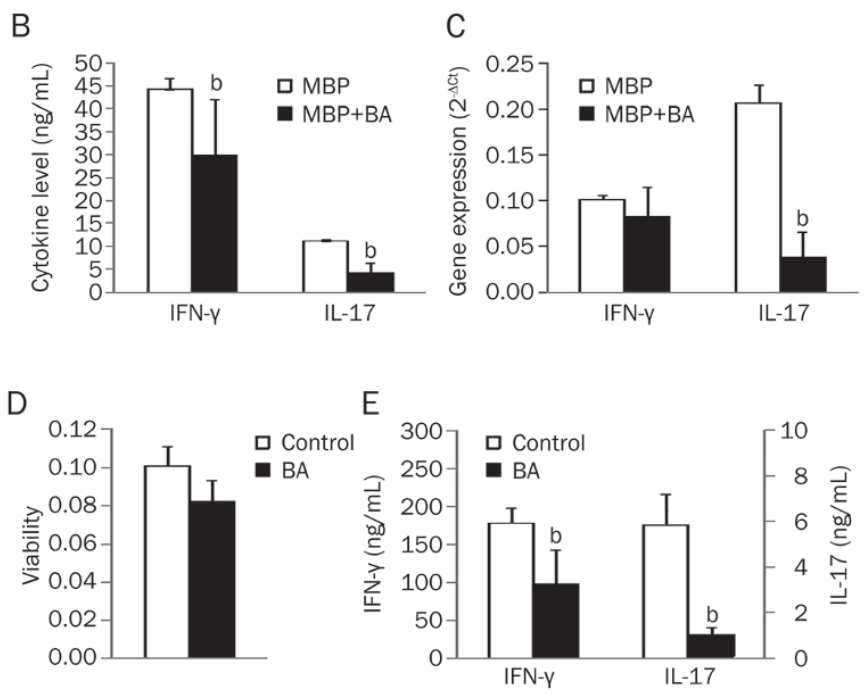

Figure 1. The influence of BA on IFN- $y$ and IL-17 generation and viability of MBP-specific T cells. Rats were immunized with MBP and CFA. DLNC were obtained from popliteal lymph nodes at 8-10 d after immunization. SCC were obtained from spinal cords at the peak of EAE. DLNC (2.5× $\left.10^{6} / \mathrm{mL}\right)$ were stimulated with $\mathrm{MBP}(10 \mu \mathrm{g} / \mathrm{mL})$ in the presence of various concentrations of $B A(A)$ or $50 \mu \mathrm{mol} / \mathrm{L} \mathrm{BA}(B, C)$. SCC were cultivated without stimulation in the absence or presence of $50 \mu \mathrm{mol} / \mathrm{L} B A(D, E)$. After $24 \mathrm{~h}$ of cultivation, cell-free culture supernatants were collected for cytokine determination (A, B, E), cell viability was measured by AP assay (A) or MTT assay (D), and DLNC were used for RT-PCR (C). Results are presented as means $\pm S D$ of values obtained in samples from two (A), eight (B), or three (C, D, E) rats. ${ }^{b} P<0.05$ represents a statistically significant difference between the cultures grown in the absence (Control) and presence of BA.

(to $11 \%$ of the value obtained in untreated cultures). On the contrary, the maximal effect on IL-17 release achieved with $25 \mu \mathrm{mol} / \mathrm{L}$ BA was less potent (36\% of the value obtained in untreated cultures). Higher BA concentrations did not decrease IL-17 production in DLNC additionally (Figure 1A). Further, SCC were isolated at the peak of EAE and cultivated for $24 \mathrm{~h}$ without stimulation, whereas the BA that was applied from the beginning of the cultivation in $50 \mu \mathrm{mol} / \mathrm{L}$ concentration had limited effect on SCC viability (Figure 1D). Once again, BA was a potent inhibitor of IL-17 generation and was fairly effective against IFN- $\gamma$ production (Figure 1E). Thus, 

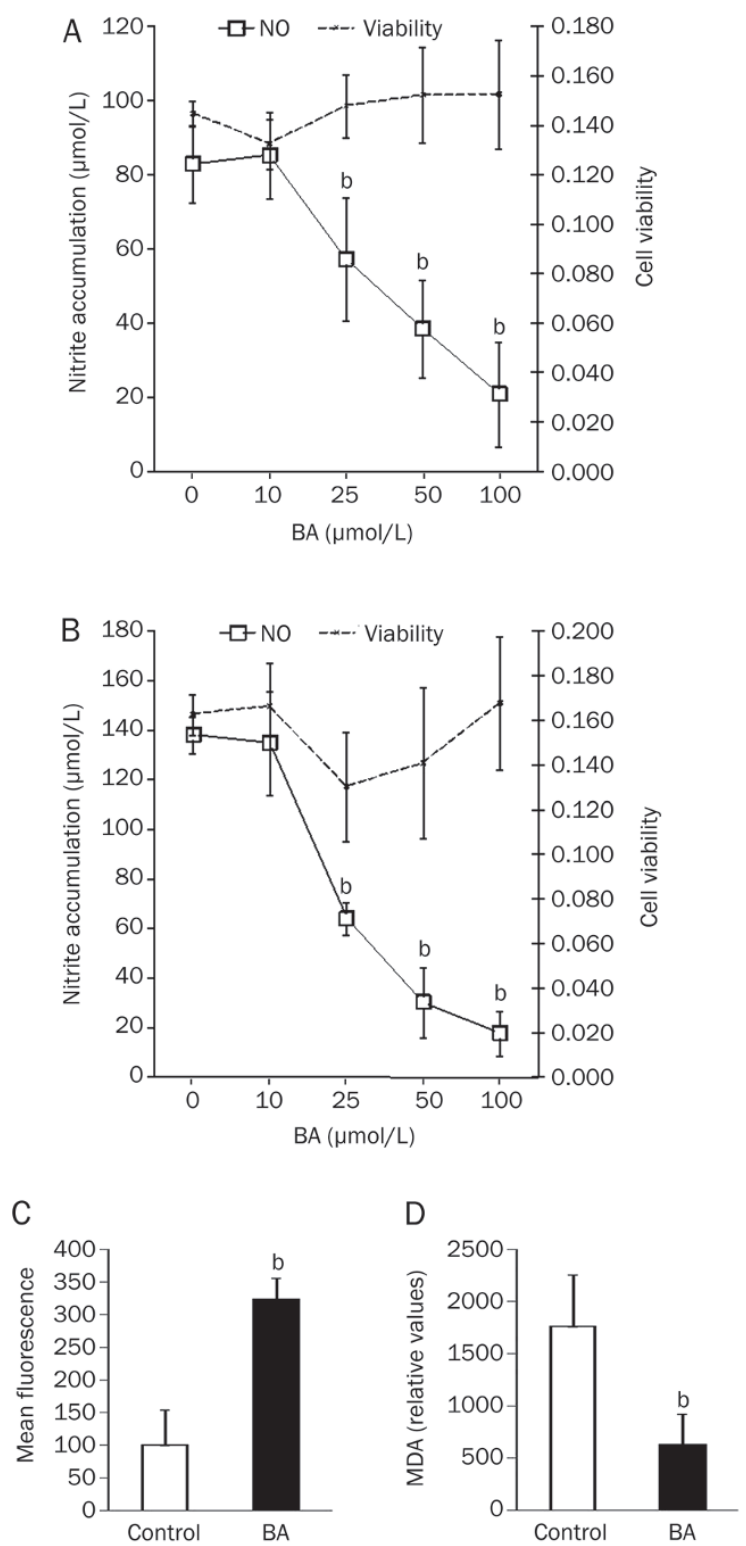

Figure 2. The influence of BA on NO production and viability of SPC, $\mathrm{PC}$, and ROS generation and lipid peroxidation in PC. SPC $\left(5 \times 10^{6} / \mathrm{mL}\right)$ stimulated with $2.5 \mu \mathrm{g} / \mathrm{mL}$ ConA $(A)$ and $P C\left(1 \times 10^{6} / \mathrm{mL}\right)$ stimulated with LPS $10 \mathrm{ng} / \mathrm{mL}(B, D)$ were cultured in the presence of various concentrations of BA. After $24 \mathrm{~h}$ of cultivation, cell-free culture supernatants were collected for nitrite determination and cell viability was measured by MTT assay (SPC) or CV (PC). PC $\left(1 \times 10^{6} / \mathrm{mL}\right)$ were cultivated in the presence of $1 \mu \mathrm{mol} / \mathrm{L}$ DHR for $30 \mathrm{~min}$ and then stimulated with $50 \mu \mathrm{mol} / \mathrm{L} \mathrm{BA}$ for $1 \mathrm{~h}(\mathrm{C})$. PC $\left(4 \times 10^{6} / 1.5 \mathrm{~mL}\right)$ were cultivated in the presence or absence of $50 \mu \mathrm{mol} / \mathrm{L}$ BA for $24 \mathrm{~h}$ and subsequently a TBARS assay was performed (D). Results are presented as mean $\pm S D$ of values obtained in four (A, B) or three (C, D) independent experiments. ${ }^{b} P<0.05$ represents a statistically significant difference between the cultures grown in the absence (Control) and presence of BA.

BA inhibited production of IFN- $\gamma$ and IL-17 in encephalitogenic cells that were re-stimulated in vitro with $\mathrm{MBP}$ or in vivo within the CNS.
The effect of BA on NO generation in splenocytes and on NO generation, ROS production and lipid peroxidation in peritoneal macrophages

SPC and PC were isolated from untreated rats and stimulated with ConA and LPS, respectively. Various concentrations of $\mathrm{BA}$, up to $100 \mu \mathrm{mol} / \mathrm{L}$, were added simultaneously and cultivation lasted for $24 \mathrm{~h}$. Subsequently, nitrites were determined in culture supernatants and cell viability was analyzed. In both SPC (Figure 2A) and PC (Figure 2B), BA did not significantly influence viability in the applied concentrations, whereas it had a clear dose-dependent down-regulatory effect on $\mathrm{NO}$ production. Estimated $\mathrm{IC}_{50}$ values were $58 \mu \mathrm{mol} / \mathrm{L}$ for SPC and $42 \mu \mathrm{mol} / \mathrm{L}$ for PC. In contrast, ROS generation in PC was induced by $1 \mathrm{~h}$ treatment with BA $(50 \mu \mathrm{mol} / \mathrm{L})$ (Figure $2 \mathrm{C}$ ), but lipid peroxidation was reduced after $24 \mathrm{~h}$ of incubation (Figure 2D). Thus, BA had the opposite effect on the production of the main reactive species in macrophages, ie it inhibited synthesis of nitrogen and induced the generation of oxygen reactive species, yet its net effect on lipid peroxidation in these cells was negative.

The effect of BA on ROS generation, iNOS expression and CXCL12 expression in astrocytes

Astrocytes were stimulated with ConASn, which contains numerous inflammatory mediators and thus mimics the inflammatory milieu present in the CNS during neuroinflammation. To detect ROS generation, MGC, primary astrocytes and $\mathrm{C} 6$ cells were stimulated with ConASn in the presence of $50 \mu \mathrm{mol} / \mathrm{L}$ BA for $1 \mathrm{~h}$. BA potently stimulated ROS generation in all of the cells examined (Figure 3A). Astrocytes were also treated with ConASn for $24 \mathrm{~h}$ in the absence or presence of BA $(50 \mu \mathrm{mol} / \mathrm{L})$ and iNOS and CXCL12 gene expression was determined. BA significantly reduced iNOS mRNA expression in the astrocytes, but the downregulation did not reach a significant level at the protein level (Figure 3B, 3C). Also, expression of the CXCL12 gene, but not of the CXCL12 protein, was inhibited by BA (Figure 3B, 3C). Finally, BA inhibited ConASn-induced lipid peroxidation in C6 cells (Figure 3D) and astrocytes (data not shown). Thus, similar to macrophages, astrocytes responded to the BA treatment with up-regulation of ROS, but the net effect of the BA on lipid peroxidation was negative.

\section{Discussion}

Here, we present BA as a potent modulator of the synthesis of molecules that are relevant for neuroinflammation. BA inhibits generation of the pro-inflammatory cytokines IL-17 and IFN- $\gamma$ in T cells and NO in macrophages, but stimulates generation of CNS-tissue deleterious ROS in macrophages and astrocytes. Importantly, BA downregulates lipid peroxidation in macrophages and astrocytes.

BA potently inhibited IL-17 and IFN-ץ production in MBPspecific $\mathrm{T}$ cells isolated from lymph nodes or the CNS, which suggests that BA intensively inhibits Th17 and Th1 effector functions. IL-17-producing Th17 cells and IFN- $\gamma$-producing Th1 cells are considered to be among the major pathogenic 


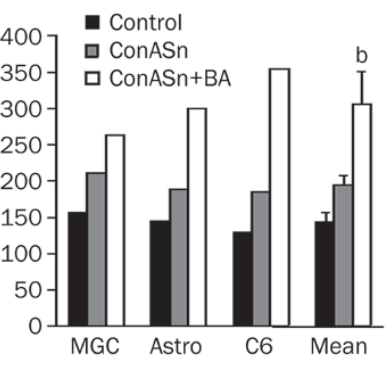

B

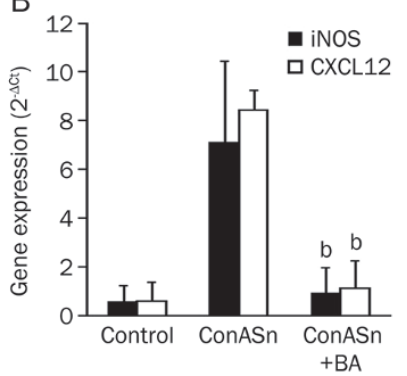

C

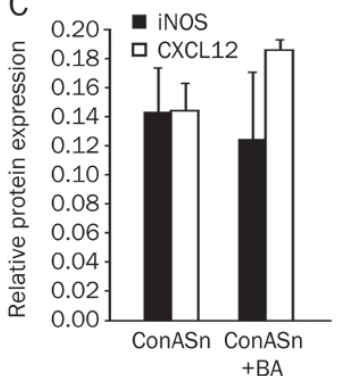

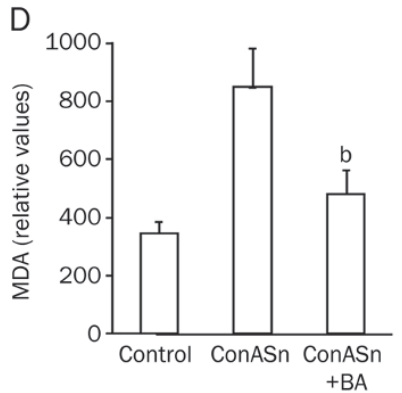

Figure 3. The influence of BA on ROS production, lipid peroxidation, and CXCL12 and iNOS expression in astrocytes and C6 cells. Astrocytes, MGC, or C6 cells $\left(1.5 \times 10^{5} / \mathrm{mL}\right)$ were pre-incubated with $1 \mu \mathrm{mol} / \mathrm{L}$ DHR for $30 \mathrm{~min}$ and then stimulated with $20 \%$ ConASn in the presence or absence of 50 $\mu \mathrm{mol} / \mathrm{L}$ BA. After $1 \mathrm{~h}$ of cultivation, ROS generation was determined by DHR staining and flow cytometry (A) and after $24 \mathrm{~h}$ the cells were used for detection of CXCL12 and iNOS gene expression by RT-PCR (B) or protein expression by immunoblot (C). C6 cells $\left(1.5 \times 10^{6} / 1.5 \mathrm{~mL}\right)$ were stimulated with $20 \%$ ConASn in the presence or absence of $50 \mu \mathrm{mol} / \mathrm{L}$ BA for $24 \mathrm{~h}$ and subsequently a TBARS assay was performed (D). Results are presented as mean $\pm S D$ of values obtained in at least three independent experiments. Also, results from individual experiments are presented in $A$. ${ }^{\mathrm{b}} P<0.05$ represents a statistically significant difference between the cultures stimulated with ConASn in the absence and presence of BA.

populations in the CNS autoimmunity ${ }^{[2]}$. Both IL-17 and IFN- $\gamma$ are continuously produced by DLNC and SCC in Dark Agouti rats immunized to develop $\mathrm{EAE}^{[16]}$. Furthermore, low production of IL-17 and IFN- $\gamma$ in DLNC, as well as low production of the cytokines that induce IL-17 and IFN- $\gamma$ generation (including IL-6, IL-12, and IL-23) in DLNC, have been associated with the resistance of Albino Oxford rats to EAE induction ${ }^{[17,}$ ${ }^{18]}$. Regarding MS, it has been shown that IL-17 is elevated in immune cells within the CNS and at the periphery and that it contributes to the pathogenesis of the disease, eg through distortion of the blood-brain-barrier ${ }^{[19-21]}$. It has also been shown that IFN- $\gamma$-producing cells are present within the CNS and at the periphery of MS patients ${ }^{[22]}$, and that treatment of MS patients with IFN- $\gamma$ exacerbates the disease ${ }^{[23]}$. Therefore, inhibiting IL-17 and IFN- $\gamma$ generation is relevant when modulating the EAE course and also has relevance when evaluating therapeutic efficiency in MS. Regarding the higher efficacy of the BA influence on IL-17, relative to IFN- $\gamma$, it is known that this agent potently inhibits STAT-3 signaling ${ }^{[24,25]}$, which is essential for IL-17, but not IFN- $\gamma$ production ${ }^{[26]}$. Although it was previously reported that BA moderately inhibits IFN- $\gamma$ production in human peripheral blood cells ${ }^{[27]}$, this is the first report, to the best of our knowledge, that BA is effective against IL-17 generation.

$\mathrm{NO}$ and ROS are among the main culprits for tissue damage in neuroinflammation, especially when they are produced simultaneously and when they interact to generate peroxynitrite ${ }^{[6,7]}$. BA applied in vivo has been shown to decrease both oxidative and nitrative stress in mice and rats $^{[28,29]}$. However, in our experimental setting BA consistently induced ROS generation and inhibited iNOS-mediated NO production. Consistent with our results, it was previously shown that BA inhibits NO generation in primary mouse macrophages and the RAW264.7 cell line ${ }^{[30]}$. We also show that BA inhibits synthesis of NO in mixed populations of spleen cells, as well as in astrocytes. Thus, the influence of BA on NO generation might be of pharmacological relevance when treat- ing (neuro)inflammatory disorders. However, ROS induction in macrophages and astrocytes by BA is a greatly unwanted effect of this agent, as ROS present a threat to the CNS tissue in neuroinflammation ${ }^{[31]}$. Still, simultaneous inhibition of $\mathrm{NO}$ production should prevent the generation of peroxynitrite, which is the major mediator of oxidative stress and excitotoxicity in the pathogenesis of MS and $\mathrm{EAE}^{[6,32]}$. Indeed, in our system, BA downregulated the oxidative degradation of lipids, ie lipid peroxidation, both in LPS-stimulated macrophages and cytokine-stimulated astrocytes. This clearly shows that although BA stimulates ROS generation in these cells its overall effect is cytoprotective. Also, as ROS generation by macrophages is one of the essential effector mechanisms for destroying pathogens, potentiating ROS production in macrophages by BA might be a favorable pharmacological property of the agent in the treatment of infectious diseases.

It has recently been determined that CXCL12 has a major regulatory role in the control of encephalitogenic cell entry into the CNS in neuroinflammation ${ }^{[10]}$. Here, we observed that BA inhibits CXCL12 gene expression, but not its generation, in astrocytes, thus suggesting a neutral effect of the agent on the CXCL12-mediated anti-inflammatory effect in the CNS. Besides astrocytes, endothelial cells are an important source of CXCL12 in regulating immune cell entry into the CNS, and therefore exploration of the influence of BA on endothelial cells is needed. Such studies would allow further insight into the influence of BA on neuroinflammation through the modulation of CXCL12 expression.

In conclusion, BA potently modulates the generation of various molecules that are important for the pathogenesis of neuroinflammatory disorders such as MS and EAE. While inhibiting the production of the proinflammatory cytokines IL-17 and IFN- $\gamma$ and NO, BA also stimulates the production of potentially toxic ROS. Thus, further investigation of the influence of BA is warranted, especially regarding the in vivo application of the agent in EAE and other animal models of neuroinflammation. Special attention should be given to the 
way that BA is administered to experimental animals. It is clear that the application of BA systemically would affect the immune cells in lymphoid tissues and circulation. However, it is debatable whether BA would be able to affect cells within the CNS, either immune or resident, if applied in this way. Although data on the ability of BA to cross an intact bloodbrain barrier (BBB) are, to the best of our knowledge, unavailable, it is conceivable that a complex triterpenoid compound such as BA does not passively cross this barrier. However, during neuroinflammation, eg in EAE, the BBB is affected as well, and it becomes more permeable for transport of complex molecules ${ }^{[33]}$. The possibility of barrier circumvention, through BBB disruption, prodrugs, molecular Trojan horses or nanocarriers, should also be considered ${ }^{[34]}$. Similarly, the possibility of chemically modifying the BA to make it able to cross the BBB seems very attractive, as it has been shown to be effective for other triterpenoids, eg oleanolic acid in $\mathrm{EAE}^{[35]}$. As a matter of fact, the strategy of chemical modification has already been applied to betulinic acid, as its derivatives have been investigated for their anti-cancer properties ${ }^{[36,37]}$.

Finally, besides demonstrating the potential therapeutic effects in neuroinflammation, our results also contribute to the understanding of BA anti-cancer properties. It is well appreciated that chronic inflammation paves the road for cancerogenesis, while its prevention or restriction might aid tumorogenesis impediment ${ }^{[38]}$. Thus, the anti-inflammatory properties of BA presented here might contribute to its overall anti-cancer therapeutic potential.

\section{Acknowledgements}

This work was supported by the Ministry of Education and Science of the Republic of Serbia (173035, 175038, and 173013). The authors would like to thank BioSolutions Halle GmbH for betulinic acid.

\section{Author contribution}

Jana BLAŽEVSKI, Filip PETKOVIĆ, Miljana MOMČILOVIĆ, and Djordje MILJKOVIĆ performed research; Marija MOSTARICA STOJKOVIĆ and Djordje MILJKOVIĆ designed research, analyzed data and wrote the paper; Reinhard PASCHKE and Goran N KALUĐEROVIĆ contributed new reagents.

\section{References}

1 Constantinescu CS, Farooqi N, O'Brien K, Gran B. Experimental autoimmune encephalomyelitis (EAE) as a model for multiple sclerosis (MS). Br J Pharmacol 2011; 164: 1079-106.

2 El-behi M, Rostami A, Ciric B. Current views on the roles of Th1 and Th17 cells in experimental autoimmune encephalomyelitis. J Neuroimmune Pharmacol 2010; 5: 189-97.

3 Misko TP, Trotter JL, Cross AH. Mediation of inflammation by encephalitogenic cells: interferon gamma induction of nitric oxide synthase and cyclooxygenase 2. J Neuroimmunol 1995; 61: 195204.

4 Hewett SJ, Misko TP, Keeling RM, Behrens MM, Choi DW, Cross AH. Murine encephalitogenic lymphoid cells induce nitric oxide synthase in primary astrocytes. J Neuroimmunol 1996; 64: 201-8.
5 Haider L, Fischer MT, Frischer JM, Bauer J, Höftberger R, Botond G, et al. Oxidative damage in multiple sclerosis lesions. Brain 2011; 134: 1914-24.

6 Cross AH, Manning PT, Stern MK, Misko TP. Evidence for the production of peroxynitrite in inflammatory CNS demyelination. J Neuroimmunol 1997; 80: 121-30.

7 Smith KJ, Kapoor R, Felts PA. Demyelination: the role of reactive oxygen and nitrogen species. Brain Pathol 1999; 9: 69-92.

8 Okuda Y, Sakoda S, Fujimur H, Yanagihara T. Aminoguanidine a selective inhibitor of the inducible nitric oxide synthase has different effects on experimental allergic encephalomyelitis in the induction and progression phase. J Neuroimmunol 1998; 8: 201-10.

9 Miljković D, Timotijević G, Mostarica Stojković M. Astrocytes in the tempest of multiple sclerosis. FEBS Lett 2011; 585: 3781-8.

10 Momcilović M, Mostarica-Stojković M, Miljković D. CXCL12 in control of neuroinflammation. Immunol Res 2012; 52: 53-63.

11 Saidha S, Eckstein C, Calabresi PA. New and emerging disease modifying therapies for multiple sclerosis. Ann N Y Acad Sci 2012; 1247: 117-37.

12 Yogeeswari P, Sriram D. Betulinic acid and its derivatives: a review on their biological properties. Curr Med Chem 2005; 12: 657-66.

13 Kommera H, Kaluđerović GN, Kalbitz J, Paschke R. Lupane triterpenoids - betulin and betulinic acid derivatives induce apoptosis in tumor cells. Inv New Drugs 2011; 29: 266-72.

14 McCarthy KD, de Vellis J. Preparation of separate astroglial and oligodendroglial cell cultures from rat cerebral tissue. J Cell Biol 1980; 85: 890-902.

15 Draper HH, Hadley M. Malondialdehyde determination as index of lipid peroxidation. Methods Enzymol 1990; 186: 421-31.

16 Momcilović M, Miljković Z, Popadić D, Miljković D, Mostarica-Stojković M. Kinetics of IFN-gamma and IL-17 expression and production in active experimental autoimmune encephalomyelitis in Dark Agouti rats. Neurosci Lett 2008; 447: 148-52.

17 Miljkovic D, Stosic-Grujicic S, Markovic M, Momcilovic M, Ramic Z, Maksimovic-Ivanic D, et al. Strain difference in susceptibility to experimental autoimmune encephalomyelitis between Albino Oxford and Dark Agouti rats correlates with disparity in production of IL-17 but not nitric oxide. J Neurosci Res 2006; 84: 379-88.

18 Markovic M, Miljkovic D, Momcilovic M, Popadic D, Miljkovic Z, Savic E, et al. Strain difference in susceptibility to experimental autoimmune encephalomyelitis in rats correlates with $\mathrm{T}(\mathrm{H}) 1$ and $\mathrm{T}(\mathrm{H}) 17$-inducing cytokine profiles. Mol Immunol 2009; 47: 141-6.

19 Matusevicius D, Kivisäkk P, He B, Kostulas N, Ozenci V, Fredrikson S, et al. Interleukin-17 mRNA expression in blood and CSF mononuclear cells is augmented in multiple sclerosis. Mult Scler 1999; 5: 101-4.

20 Kebir H, Kreymborg K, Ifergan I, Dodelet-Devillers A, Cayrol R, Bernard $M$, et al. Human TH17 lymphocytes promote blood-brain barrier disruption and central nervous system inflammation. Nat Med 2007; 13: $1173-5$.

21 Tzartos JS, Friese MA, Craner MJ, Palace J, Newcombe J, Esiri MM, e al. Interleukin-17 production in central nervous system-infiltrating T cells and glial cells is associated with active disease in multiple sclerosis. Am J Pathol 2008; 172: 146-55.

22 Link J, Söderström M, Olsson T, Höjeberg B, Ljungdahl A, Link $H$. Increased transforming growth factor-beta interleukin-4 and interferon-gamma in multiple sclerosis. Ann Neurol 1994; 36: 79-86.

23 Panitch HS, Hirsch RL, Haley AS, Johnson KP. Exacerbations of multiple sclerosis in patients treated with gamma interferon. Lancet 1987; 18: 893-5.

24 Pandey MK, Sung B, Aggarwal BB. Betulinic acid suppresses STAT3 activation pathway through induction of protein tyrosine phosphatase 
SHP-1 in human multiple myeloma cells. Int J Cancer 2010; 127 : 282-92.

25 Shin J, Lee HJ, Jung DB, Jung JH, Lee HJ, Lee EO, et al. Suppression of STAT3 and HIF-1 alpha mediates anti-angiogenic activity of betulinic acid in hypoxic PC-3 prostate cancer cells. PLoS One 2011; 6: e21492.

26 Yang XO, Panopoulos AD, Nurieva R, Chang SH, Wang D, Watowich SS, et al. STAT3 regulates cytokine-mediated generation of inflammatory helper T cells. J Biol Chem 2007; 282: 9358-63.

27 Zdzisińska B, Rzeski W, Paduch R, Szuster-Ciesielska A, Kaczor J, Wejksza K, et al. Differential effect of betulin and betulinic acid on cytokine production in human whole blood cell cultures. Pol J Pharmacol 2003; 55: 235-8.

28 Lu Q, Xia N, Xu H, Guo L, Wenzel P, Daiber A, et al. Betulinic acid protects against cerebral ischemia-reperfusion injury in mice by reducing oxidative and nitrosative stress. Nitric Oxide 2011; 24: 132-8.

29 Nader MA, Baraka HN. Effect of betulinic acid on neutrophil recruitment and inflammatory mediator expression in lipopolysaccharide-induced lung inflammation in rats. Eur J Pharm Sci 2012; 46: 106-13.

30 Yun Y, Han S, Park E, Yim D, Lee S, Lee CK, et al. Immunomodulatory activity of betulinic acid by producing pro-inflammatory cytokines and activation of macrophages. Arch Pharm Res 2003; 26: 1087-95.

31 van Horssen J, Witte ME, Schreibelt G, de Vries HE. Radical changes in multiple sclerosis pathogenesis. Biochim Biophys Acta 2011; 1812: 141-50.

32 Gonsette RE. Oxidative stress and excitotoxicity: a therapeutic issue in multiple sclerosis? Mult Scler 2008; 14: 22-34.

33 Erickson MA, Dohi K, Banks WA. Neuroinflammation: a common pathway in CNS diseases as mediated at the blood-brain barrier. Neuroimmunomodulation 2012; 19: 121-30.

34 Martin-Banderas L, Holgado MA, Venero JL, Alvarez-Fuentes J, Fernández-Arévalo M. Nanostructures for drug delivery to the brain. Curr Med Chem 2011; 18: 5303-21.

35 Pareek TK, Belkadi A, Kesavapany S, Zaremba A, Loh SL, Bai L, et al. Triterpenoid modulation of IL-17 and Nrf-2 expression ameliorates neuroinflammation and promotes remyelination in autoimmune encephalomyelitis. Sci Rep 2011; 1: 201.

36 Kommera H, Kaluderović GN, Kalbitz J, Dräger B, Paschke R. Small structural changes of pentacyclic lupane type triterpenoid derivatives lead to significant differences in their anticancer properties. Eur J Med Chem 2010; 45: 3346-53.

37 Kommera H, Kaluderović GN, Dittrich S, Kalbitz J, Dräger B, Mueller $\mathrm{T}$, et al. Carbamate derivatives of betulinic acid and betulin with selective cytotoxic activity. Bioorg Med Chem Lett 2010; 20: 340912.

38 Lowe DB, Storkus WJ. Chronic inflammation and immunologic-based constraints in malignant disease. Immunotherapy 2011; 3: 1265-74. 